A Periodic Table

\begin{tabular}{|c|c|c|c|c|}
\hline SHELL & 1 & II & III & IV \\
\hline 1 & $1 \mathrm{H}$ & & & \\
\hline 2 & $3 \mathrm{Li}$ & $4 \mathrm{Be}$ & 5 B & $6 \mathrm{C}$ \\
\hline 3 & $11 \mathrm{Na}$ & $12 \mathrm{Mg}$ & $13 \mathrm{Al}$ & $14 S i$ \\
\hline 4 & $19 \mathrm{~K}$ & $20 \mathrm{Ca}$ & $21 \mathrm{Sc}$ & $22 \mathrm{Ti}$ \\
\hline 4 & $29 \mathrm{Cu}$ & $30 \mathrm{Zn}$ & $31 \mathrm{Ga}$ & $32 \mathrm{Ge}$ \\
\hline 5 & $37 \mathrm{Rb}$ & $38 \mathrm{Sr}$ & $39 Y$ & $40 \mathrm{Zr}$ \\
\hline 5 & $47 \mathrm{Ag}$ & $48 \mathrm{Cd}$ & $49 \ln$ & $50 \mathrm{Sn}$ \\
\hline 6 & $55 \mathrm{Cs}$ & $56 \mathrm{Ba}$ & 57 La $58-71$ & $72 \mathrm{Hf}$ \\
\hline 6 & $79 \mathrm{Au}$ & $80 \mathrm{Hg}$ & $81 \mathrm{Tl}$ & $82 \mathrm{~Pb}$ \\
\hline 7 & $87 \mathrm{Fa}$ & $88 \mathrm{Ra}$ & $89 \mathrm{Ac} 90-103$ & \\
\hline
\end{tabular}

\begin{tabular}{|l|l|l|l|l|l|l|l|l|}
\hline 6 & $58 \mathrm{Ce}$ & $59 \mathrm{Pr}$ & $60 \mathrm{Nd}$ & $61 \mathrm{Pm}$ & $62 \mathrm{Sm}$ & $63 \mathrm{Eu}$ & $64 \mathrm{Gd}$ & $65 \mathrm{~Tb}$ \\
\hline 7 & $90 \mathrm{Th}$ & $91 \mathrm{~Pa}$ & $92 \mathrm{U}$ & $93 \mathrm{~Np}$ & $94 \mathrm{Pu}$ & $95 \mathrm{Am}$ & $96 \mathrm{Cm}$ & $97 \mathrm{Bk}$ \\
\hline
\end{tabular}




\section{of the Elements}

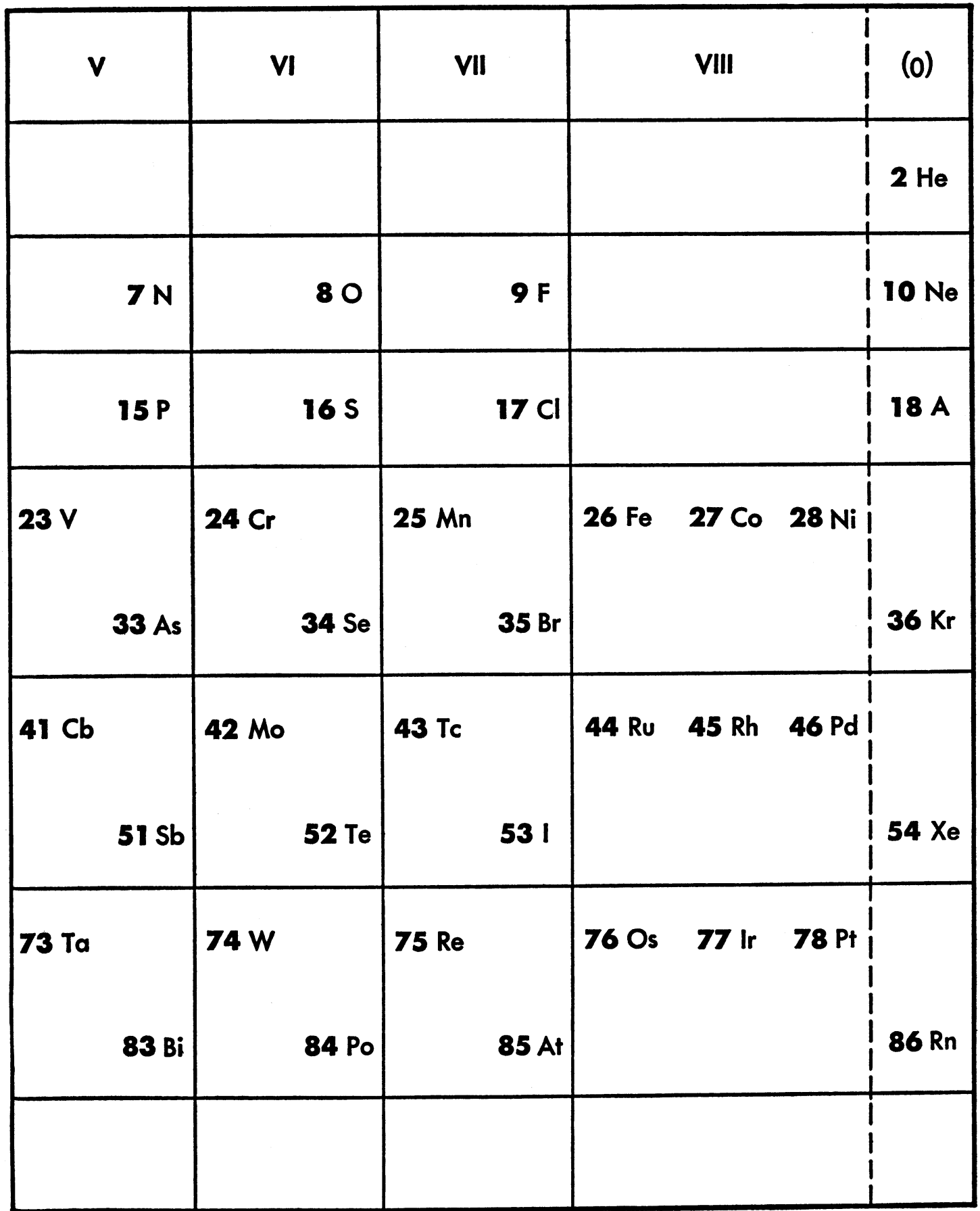

\begin{tabular}{|c|c|c|c|c|c|}
\hline $66 \mathrm{Dy}$ & $67 \mathrm{Ho}$ & $68 \mathrm{Er}$ & $69 \mathrm{Tm}$ & $70 \mathrm{Yb}$ & $71 \mathrm{LU}$ \\
\hline $98 \mathrm{Cf}$ & $99 \mathrm{Es}$ & $100 \mathrm{Fm}$ & $101 \mathrm{Md}$ & $102 \mathrm{No}$ & $103 \mathrm{LW}$ \\
\hline
\end{tabular}




\section{PHYSICS}




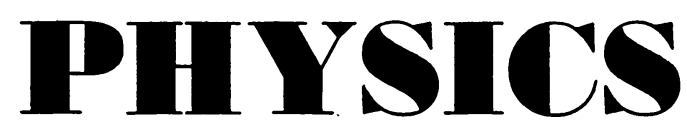

2ND EDITION

J. S. Marshall

McGill University

E. R. Pounder

McGill University

R. W. Stewart

University of British Columbia

Macmillan Education 
ISBN 978-1-349-81615-6 ISBN 978-1-349-81613-2 (eBook)

DOI 10.1007/978-1-349-81613-2

\section{(C) The Macmillan Company of Canada Limited 1967}

Softcover reprint of the hardcover 1st edition 1967 978-0-333-09613-0

All rights reserved - no part of this book may be reproduced in any form without permission in writing from the publisher, except by a reviewer who wishes to quote brief passages in connection with a review written for inclusion in magazine or newspaper.

Library of Congress Catalog Card No. 67-27060 


\section{Preface to the Second Edition}

This textbook covers the major branches of physics at a level suitable to an introductory course for University students in Science and Engineering. The order in which material is covered can be altered considerably at the discretion of the instructor, with the exceptions that an appreciable familiarity with mechanics is assumed in all later work, and that the discussion of wave motion in sound should precede the study of light. All three authors have taken part in the extensive re-writing of the earlier PHYSICS. We found four notable reasons for revisions.

There have been drastic changes in the mathematics studied before and after entrance to university for engineering or science. For students in these fields, calculus in first-year university is now almost universal. In the book, therefore, the ideas, notation and language of calculus are used from the start. In the first half of the text, a carefully helpful attitude is adopted to students new to differentiation and integration, and graphical treatments are emphasized. In the latter part of the text, particularly in electricity, the techniques of calculus are applied freely.

Technology is changing rapidly and dramatically. As a result, statements about technological applications of physics seem to date as rapidly as yesterday's newspaper. Forecasts made a decade ago are merely amusing now. An awareness of technology is maintained in the present book, but less space is devoted to it.

Scientific discoveries are also being made at a phenomenal rate. Little of the science we described in the first edition is obsolete, but much that is new has been incorporated, particularly in the section of the book on atomic physics - in the broad sense. Hyperons and Van Allen belts, unknown before, now merit mention in an introductory textbook. So we mention them, realizing that another decade of discovery will reveal some misconceptions among our insights.

Teaching is changing, too. Lecturers are being freed from the implication that they must interpret the text in every detail. Student schedules are allowing enough time for study that the direct interaction between student 
and textbook can be significant. We hope that with this book such interaction will provide a maximum of enlightenment and a minimum of misunderstanding.

J. S. Marshall

E. R. Pounder

R. W. STEWART

July 1,1967

Montreal and Vancouver, Canada 


\section{CONTENTS}

\section{MECHANICS}

CHAPTER 1. Introduction; Units of Time and Length 1

2. Kinematics 26

3. Force 73

4. Energy and Power 107

5. Friction 133

6. Angular Motion 146

7. Statics and Machines 180

8. Elasticity, Simple Harmonic Motion 210

9. Gravitation 236

10. Fluid Mechanics 260

HEAT

CHAPTER 11. Introductions to Heat 303

12. Conduction and Expansion 316

13. Molecular Theory of Gases 338

14. Kinetic Theory of Gases 363

15. The Expansion of Gases 391

16. Heat Engines and the Laws of Thermodynamics 408

17. Irreversibility 427

18. Radiation 439

19. Sizable and Attractive Molecules 459

20. Solids, Liquids, and Vapors 468

21. Water Substance and the Atmosphere 496

\section{SOUND}

Chapter 22. The Vibrations of Particles 521

23. Wave Motion in One Dimension 538

24. Waves in Two and Three Dimensions 576

25. Acoustics 614 


\section{LIGHT}

CHAPTER 26. Light and Color

27. Reflection, Refraction, and Dispersion

28. Lenses and Mirrors

29. Simple Lens Systems

30. Illumination and Optical Instruments

31. Diffraction, Interference, and Polarization

\section{ELECTRICITY AND MAGNETISM}

Chapter 32. Electric Current

33. Resistance 804

34. Chemical Effects of Current 832

35. Electrostatics $\quad 849$

36. Magnetic Effects of Current 890

37. Electromagnetic Induction 925

38. Magnetic Properties of Matter 949

39. Alternating Currents 966

40. Electronics 996

\section{ATOMIC PHYSICS}

Chapter 41. The Structure of Atoms 1023

42. Nuclear Physics 1051

43. Particle Physics 1085

APPENDIX A.1 Atomic Weights on the $\mathrm{C}^{12}$ Scale (1965) 1097

A.2 The Periodic System 1100

A.3 Systems of Units 1102

A.4 Differentials, Exponentials, and Logarithms 1104 ANSWERS TO ODD-NUMBERED PROBLEMS 1114

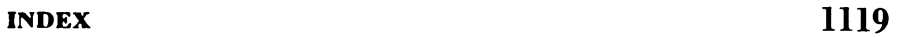

